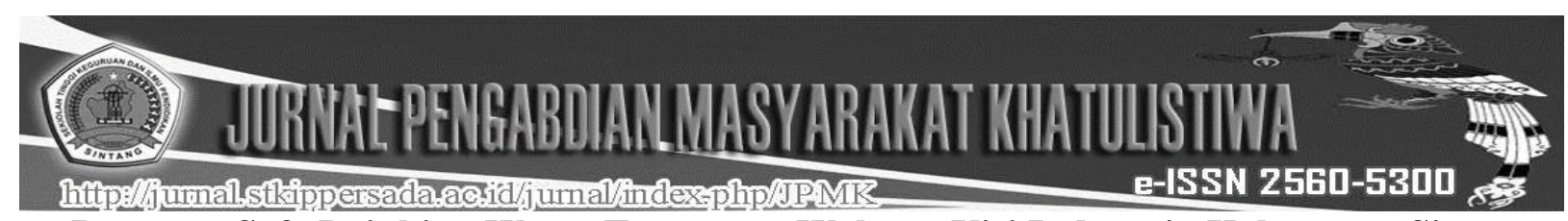

Program Safe Drinking Water Treatment Wahana Visi Indonesia Kabupaten Sintang

\author{
Margaretta Siregar ${ }^{1}$, Nelly Wedyawati ${ }^{2}$ \\ ${ }^{1}$ Area Program Manager Melawi Sintang,Word Vision Indonesia (WVI) \\ ${ }^{2}$ Dosen PGSD, STKIP Persada Khatulistiwa Sintang \\ ${ }^{1}$ Etta_siregar@yahoo.com, ${ }^{2}$ nellywedyawati@ymail.com
}

\begin{abstract}
Abstrak: Program Safe drinking water treatment adalah program yang dilakukan wahana Visi Indonesia kantor operasional melawi sintang melalui peningkatan pamahaman masyarakat tentang pengolahan air minum rumah tangga. Tujuan program adalah menurunkan angka penyakit yang disebabkan oleh air seperti diare, meningkatkan akses air bersih dan meningkatkan pamahaman masyarakat tentang sanitasi dan kebersihan. Kegiatan program di lakukan di 4 kecamatan yaitu Kecamatan tempunak, sepauk, kelam permai dan tebelian kabupaten Sintang. Adapun durasi program dilakukan sepanjang 1 agustus 2018 sampai dengan 31 agustus 2019. Sebanyak 2.342.400 PnG packet purifier didistribusikan dan berdampak kepada 43.410 orang dan $2.908 \mathrm{KK}, 84$ orang kader masyarakat mendapat peningkatan kapasitas terkait pengelolaan Air Minum rumah tangga, 43 KK di Dusun Pulau Bersatu Desa Jaya Mentari Kecamatan Tempunak hulu mendapat peningkatan akses terhadap air bersih, 357 anak mendapat peningkatan sarana sanitasi di sekolah serta sebanyak 1.357 anak mendapat pengetahuan tentang cuci tangan pakai sabun di sekolah. Dengan program ini maka diharapkan masyarakat semakin memahami pentingnya menerapkan prilaku hidup bersih sehat dengan mengelola sanitasi khususnya pilar 1, 2 dan 3 Sanitasi total berbasis masyarakat untuk tidak Buang air besar sembarangan, cuci tangan pakai sabun dan pengelolaan air minum rumah tangga.
\end{abstract}

Kata Kunci: Sanitasi, Purifier, Cuci Tangan, Diare

Abstract: The Safe drinking water treatment program is a program that is carried out by the Indonesian Vision vehicle melawi sintang operational office through increased public understanding of household drinking water treatment. The aim of the program is to reduce the number of diseases caused by water such as diarrhea, increase access to clean water and increase public understanding of sanitation and hygiene. The program activities were carried out in 4 sub-districts namely Tempunak, Sepauk, Permam, and Sintang Districts. The duration of the program was carried out from 1 August 2018 to 31 August 2019. A total of 2,342,400 PnG packet purifiers were distributed and affected 43,410 people and 2,908 households, 84 community cadres received capacity building related to household drinking water management, 43 households in Pulau Hamlet Bersatu Desa Jaya Mentari Upstream Sub-district has access to clean water, 357 children have improved sanitation facilities in schools and 1,357 children have knowledge about washing hands with soap in schools. With this program it is hoped that the community will increasingly understand the importance of implementing healthy hygiene behavior by managing sanitation, especially pillars 1, 2 and 3 Community-based total sanitation not to defecate carelessly, washing hands with soap and managing household drinking water.

Key words: Sanitation, Purifier, Hand Washing, Diarrhea 


\section{IUIMUHEPENGABDAMLMASYARAKAT KHATULISTIWA}

http:/funnal.stkippersada.acid/jumal/index-php/JPMR

\section{PENDAHULUAN}

Di Kalimantan Barat sanitasi dasar masih menjadi masalah dimana berdasarkan website Sanitasi Total Berbasis Masyarakat baseline angka sanitasi kepemilikan Jamban sehat di Kalimantan barat yaitu 36,8\% lebih tinggi dibanding kabupaten Sintang yaitu sebesar $24,52 \%$ terdapat kemajuan yang cukup tinggi dikabupaten sintang di mana terjadi peningkatan akses di tahun 2019 menjadi 52,84\% masih lebih rendah dibanding kemajuan akses sanitasi di tahun 2019 Kalimantan Barat yang mencapai angka

$62,17 \%$ (http://monev.stbm.kemkes.go.id/index.php/pilar _1). Dengan geografis wilayah yang dilewati aliran sungai dimana kebiasaan buang air besar sembarangan khususunya di sungai masih menjadi perilaku sehari hari maka bisa dipastikan bahwa sumber air sungai yang juga sehari hari digunakan untuk keperluan rumah tangga tidak layak digunakan. Adanya tambang emas illegal yang menggunakan bahan kimia dalam prosesnya juga menyebabkan cemaran bagi air sungai yang digunakan oleh masyarakat.

Program safe drinking water treatment yang dilakukan oleh Wahana Visi Indonesia Operasional Melawi Sintang dilakukan dalam rangka mengurangi dampak terkait dengan akses air yang kurang layak sehingga bisa mengurangi permasalahan kesehatan khususnya penyakit yang disebabkan oleh akses air yang tidak baik seperti diare. Program ini dilakukan dengan pemberdayaan masyarakat dan peningkatan pemahaman masyarakat baik orang dewasa maupun anak tentang pentingnya mengelola air minum rumah tangga melalui pendistribusian PnG Purifier dan penyampaikan metode pengolahan air minum rumah tangga lainnya. Adapun program di lakukan di 4 kecamatan di kabupaten sintang yaitu kecamatan tempunak, sepauk, tebelian dan kelam permai dengan jumlah desa terdampak sebanyak 24 Desa.

Penting untuk menggunakan format pelaporan standar untuk inspeksi sanitasi dan pemetaan daerah tangkapan air untuk memastikan bahwa informasi yang dikumpulkan oleh staf yang berbeda dapat diandalkan dan bahwa informasi yang dikumpulkan pada sumber air yang berbeda dapat dibandingkan. Perilaku hidup bersih dan sehat merupakan suatu hal yang sangat penting dan menjadi tantangan tersendiri dalam mewujudkan kesehatan masyarakat. Hal ini disebabkan karena disamping kesadaran masyarakat akan hidup sehat masih diragukan, sarana untuk berperilaku hidup bersih dan sehat di masyarakat pun dirasa masih sangat terbatas. Era Otonomi Daerah saat ini menuntut pemerintah daerah memberikan peningkatan pelayanan kepada masyarakat di semua sektor pembangunan. Salah satu bentuk pelayanan dasar yang menjadi tugas dan tanggungjawab pemerintah daerah kabupaten/kota adalah penyediaan kebutuhan air minum dan sanitasi 
yang sangat berkaitan erat dengan kondisi

kesehatan masyarakat.

Sektor air minum dan sanitasi merupakan pelayanan publik yang mempunyai kaitan erat dengan pengentasan kemiskinan. (Christ \& Margaretha, 2016). Tidak memadainya prasarana dan sarana air minum dan sanitasi, khususnya di pedesaan dan daerah pinggiran kota (peri urban) berpengaruh buruk pada kondisi kesehatan dan lingkungan yang memiliki dampak lanjutan terhadap tingkat perekonomian keluarga. Penyediaan prasarana dan sarana air minum dan sanitasi yang baik akan memberikan dampak pada peningkatan kualitas lingkungan dan kesehatan masyarakat, serta waktu yang dapat dihemat dari usaha untuk mendapatkan air minum dan sanitasi yang baik. Ketiga dampak tersebut akan memberikan dampak lanjutan berupa peningkatan produktivitas masyarakat. Program Safe drinking water treatment adalah program yang dilakukan wahana Visi Indonesia kantor operasional melawi sintang melalui peningkatan pamahaman masyarakat tentang pengolahan air minum rumah tangga. Tujuan program adalah menurunkan angka penyakit yang disebabkan oleh air seperti diare, meningkatkan akses air bersih dan meningkatkan pamahaman masyarakat tentang sanitasi dan kebersihan.

\section{METODE PELAKSANAAN}

Program dilakukan sepanjang 1 Agustus 2018 31 Agustus 2019 dengan kegiatan yang dilakukan diantaranya

1. Pelatihan Sanitasi total berbasis masyarakat khususnya pilar pengelolaan Air Minum Rumah tangga kepada tenaga kesehatan dan kader kesehatan desa

2. Sosialisasi 5 metode pengolahan air minum (Rebus, Sodis, Kougulasi dan Flokuasi, keramik filter dan Aquatab) kepada masyarakat dan anak

3. Sosialisasi cuci tangan pakai sabun kepada anak melalui sekolah

4. Perbaikan sarana akses air bersih desa

5. Penyediaan sarana sanitasi di sekolah melalui penambahan akses toilet dan ferocement

6. Pembuatan standar operasional prosedur penyediaan air pada saat bencana

\section{HASIL DAN PEMBAHASAN}

Sepanjang program yang dilakukan hasil yang dicapai adalah

1. Sebanyak 2.342.400 packet $\mathrm{PnG}$ purifier terdistribusi kepada 43.410 orang dari 2.908 rumah tangga

2. 84 tenaga kesehatan dan kader masyarakat di latih tentang sanitasi total berbasis masyarakat pilar pengelolaan air minum rumah tangga

3. $43 \mathrm{KK}$ di dusun pulau bersatu desa jaya mentarai kecamatan tempunak mendapat perbaikan akses air bersih 


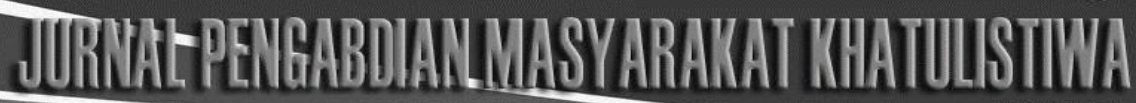

e-ISSN 25E0-5300

http://iumalstkippersada:ac:id/jurnal/index:php/JPMT

4. Tersediakan SOP penyedian air bersih pada tanga pakai sabun serta penampungan Air saat bencana di kabupaten sintang yang telah Hujan dengan ferocement di simulasikan di desa temiang Kapuas 6. 1.375 siswa mendapat peningkatan kecamatan sepauk

5. 305 orang siswa dari 2 sekolah mendapat pengetahuan tentang cuci tangan pakai sabun peningkatan akses sanitasi toilet, sarana cuci Berdasarkan monitoring dan evaluasi yang dilakukan 1-14 Juli 2019 dengan metode pengambilan sample pada tabel 1 .

Tabel 1. Pembagian Sample Evaluasi Program

\begin{tabular}{|c|l|c|}
\hline $\begin{array}{c}\text { Supervision } \\
\text { Area (SA) }\end{array}$ & \multicolumn{1}{|c|}{ Name of Villages } & $\begin{array}{c}\text { Number of } \\
\text { Sample (HH) }\end{array}$ \\
\hline SA 1 & Kupan Jaya, Kuala Tiga, Sungai Buluh dan Jaya Mentari & 19 \\
\hline SA 2 & Nanga Tempunak, Tanjung Perada, Mensiap Baru & 19 \\
\hline SA 3 & Tanjung Hulu, Gernis Jaya and Nanga Sepauk & 19 \\
\hline SA 4 & Kenyauk and Sungai Raya & 19 \\
\hline SA 5 & Sinar Harapan and Temiang Kap & 19 \\
\hline
\end{tabular}

diketahui bahwa dengan pemberian paket

purifier respon yang disampaikan oleh

masyarakat yang mendapat adalah seperti tabel 1

Tabel 2. Respon Masyarakat Dengan pemberian Purifier

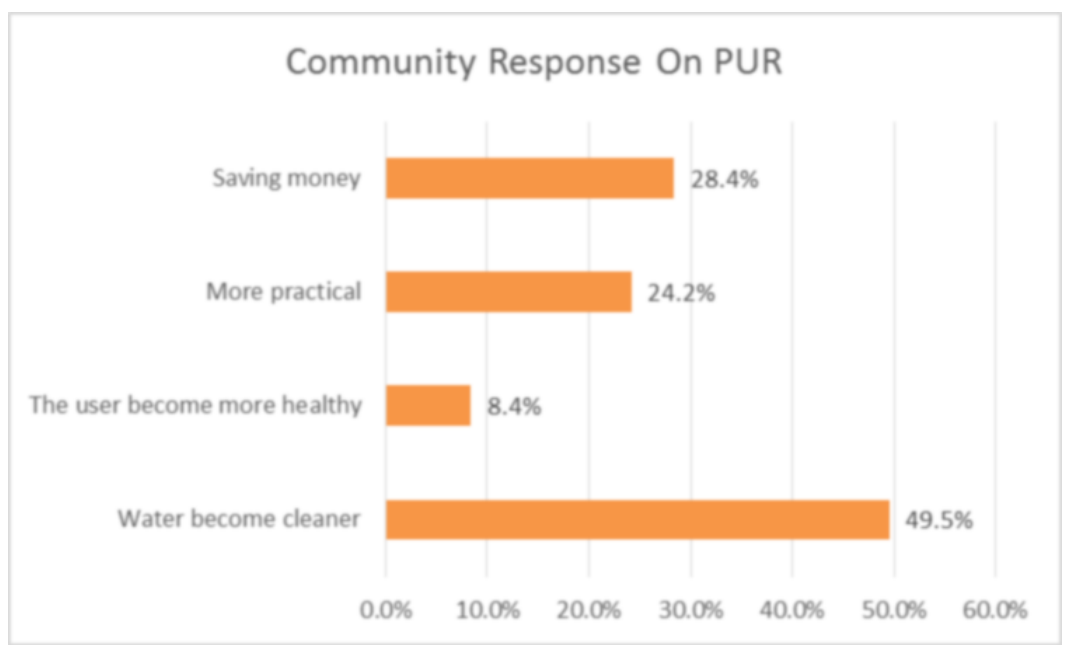




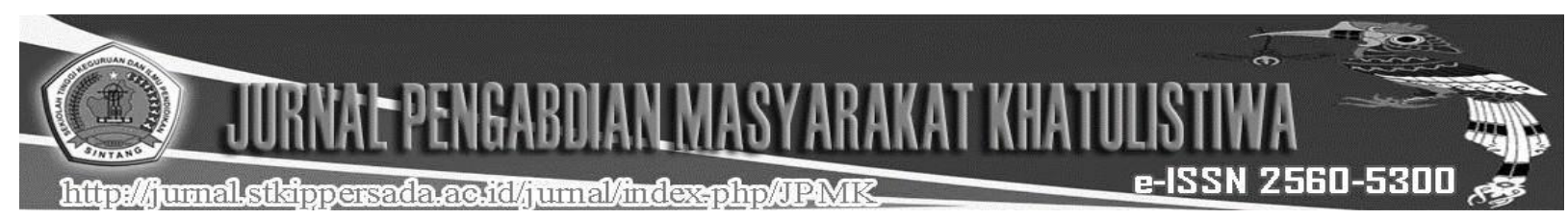

Dari tabel 49,5\% masyarakat menyatakan bahwa menghemat biaya. Dalam survey juga dilakukan dengan pemberian purifier maka air yang mereka pengukuran sumber air yang digunakan gunakan lebih bersih serta lebih praktis dan bisa masyarakat untuk diminum.

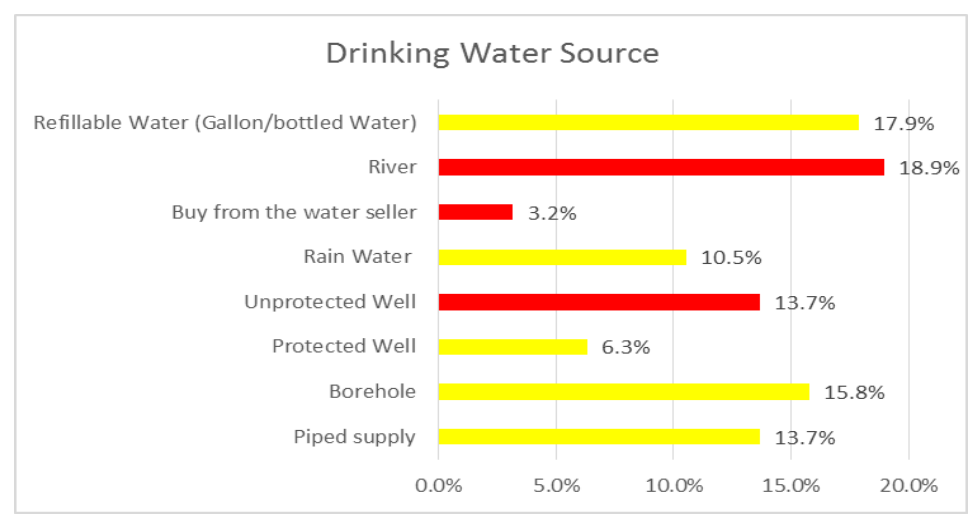

Note:

$\square$ : Safe and protected

: Unsafe and unprotected

Gambar 1. Sumber Air yang digunakan

Dari tabel 3 diketahui bahwa 17,9\% responden menggunakan air galon sebagai sumber air minum dan masih ada total $35,8 \%$ responden yang masih menggunaan sumber air yang tidak aman dan terlindungi. Evaluasi juga mengukur rumah tangga yang menggunakan fasilitas air minum Dasar. 

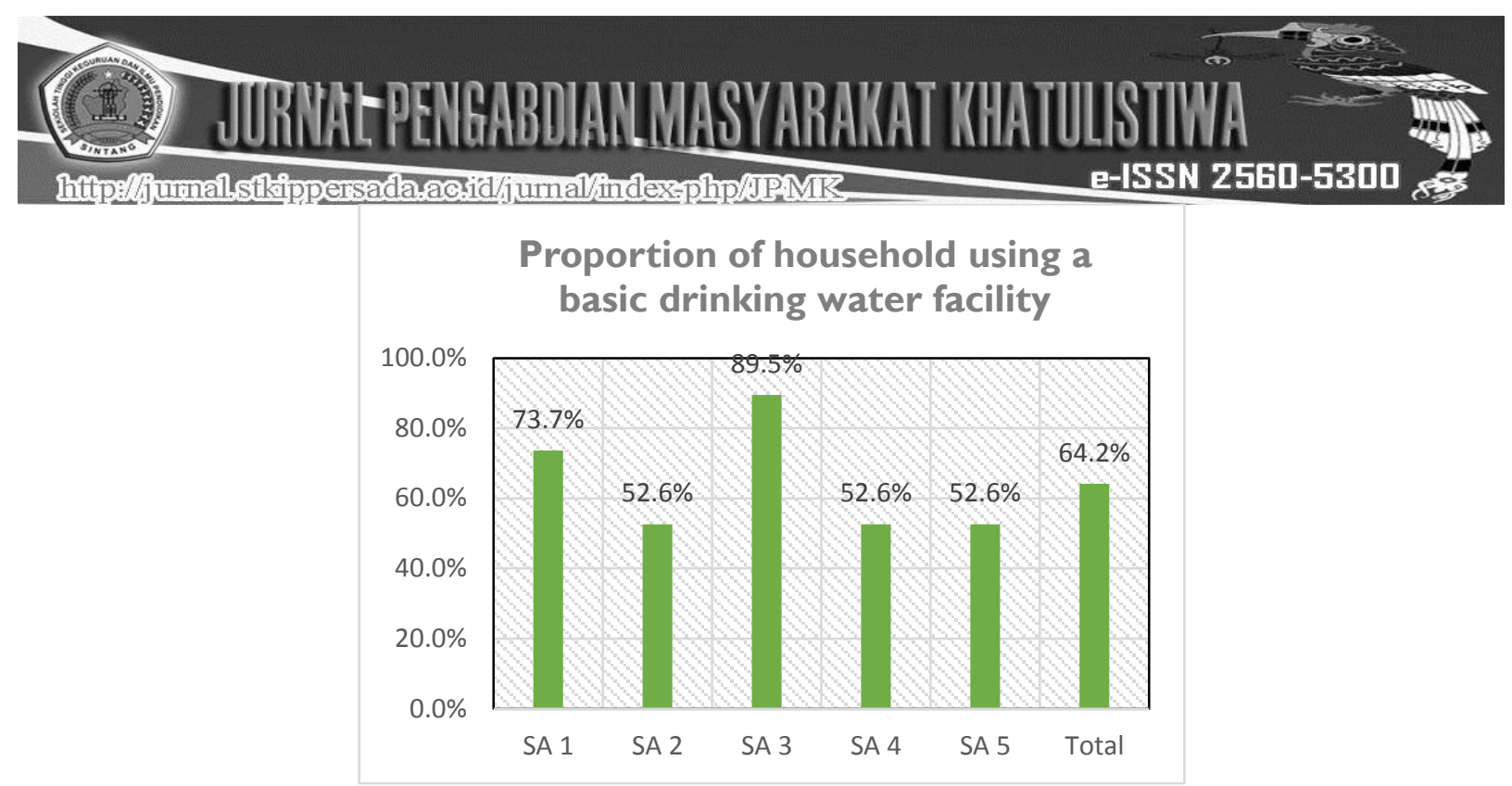

Gambar 2. Proporsi Rumah tangga yang menggunakan akses air minum dasar

Dari hasil evaluasi survey, $62,1 \%$ resoponden mengatakan bahwa air yang digunakan merupakan sumber air minum yang baik dan aman dan 37,9\% dari responden mengatakan air yang digunakan sedikit kotor dan masih ada yang menggunakan air sungai sebagai sumber air minum. (Muhammad, Samira, Faryal, \& Jamal, 2013), Berbagai bau dan rasa mungkin ada di dalam air. Rasa umumnya diklasifikasikan dalam tiga kelompok manis, sedang dan payau. Rasa dalam air dapat ditelusuri ke sejumlah faktor termasuk bahan organik yang membusuk, organisme hidup, zat besi, pencampuran limbah industri, dll. Kualitas air adalah karakteristik fisik, kimia, dan biologis air dalam kaitannya dengan perangkat standar. Parameter ini terkait langsung dengan keamanan air minum untuk penggunaan manusia. Kualitas air parameter memberikan informasi penting tentang kesehatan badan air. Parameter ini digunakan untuk mencari tahu kualitas air untuk keperluan minum

\section{SIMPULAN}

1. Masih ada wilayah dan masyarakat yang belum mendapatkan akses air bersih untuk air minum sehingga perlu peningkatan, pembuatan dan perbaikan sarana akses air bersih

2. Peningkatan pengetahuan dapat meningkatkan perubahan perilaku bersih dan sehat (Muhammad, Samira, Faryal, \& Jamal, 2013)

3. Perubahan perilaku perlu di monitoring terus menerus

4. Tujuan program untuk menurunkan angka penyakit diare tidak bisa diukur karena tidak ada baseline survey awal sebelum memulai program 
umalstkippersada.actid/jurnal/index:php/JPM

5. Pemberian PnG Purifier menolong

masyarakat untuk mendapatkan akses air

bersih

\section{DAFTAR RUJUKAN}

Christ, Margaretha, Fathurrohman. 2016. Evaluasi Program Penyediaan Air Minum dan Sanitasi Berbasis Masyarakat (PAMSIMA. Laporan. Semarang: Administrasi Publik Fakultas Ilmu Sosial dan Ilmu Politik Universitas Diponegoro.

Mohsin, M., Safdar, S., Asghar, F., Jamal, F. 2013. Assessment of Drinking Water Quality and its Impact on Residents Health in Bahawalpur City. International Journal of Humanities and Social Science Vol. 3 No. 15 August 2013. www.ijhssnet.com

Wedyawati, N., Lisa, Y. 2019. Peningkatan Rasa Kesadaran Bahaya Minuman Keras dengan Pendekatan Eksperimen Melalui PPL-KKM di SDN 11 Bora Desa Kecamatan Sayan Kabupaten Melawi. Jurnal Pengabdian Masyarakat Khatulistiwa Volume 2 Nomor 1 April 2019.

World Health Organization (WHO). 2008. WHO Library Cataloguing-in-Publication Data Guidelines for drinking-water quality [electronic resource]: incorporating 1st and 2nd addenda, Vol.1, Recommendations. - 3rd ed. Geneva.

WHO. 2004. Guidelines for Drinking-Water Quality (3rd Ed., Vol. 1). Geneva: World Health Organization (WHO). 